\title{
A New Paroxetine-Based GRK2 Inhibitor Reduces Internalization of the $\mu$-Opioid Receptor ${ }^{\text {[ }}$
}

\author{
(D) Renee A. Bouley, (1)Zara Y. Weinberg, Helen V. Waldschmidt, Yu-Chen Yen, \\ Scott D. Larsen, (Manojkumar A. Puthenveedu, and John J.G. Tesmer \\ Life Sciences Institute (R.A.B., H.V.W.), Departments of Medicinal Chemistry (H.V.W., S.D.L.) and Pharmacology (R.A.B., Z.Y.W., \\ M.A.P.), and Vahlteich Medicinal Chemistry Core, College of Pharmacy (H.V.W., S.D.L.), University of Michigan, Ann Arbor, \\ Michigan; and Departments of Biological Sciences and of Medicinal Chemistry and Molecular Pharmacology (Y.-C.Y., J.J.G.T.), \\ Purdue University, West Lafayette, Indiana
}

Received October 23, 2019; accepted March 18, 2020

\section{ABSTRACT}

G protein-coupled receptor (GPCR) kinases (GRKs) play a key role in terminating signals initiated by agonist-bound GPCRs. However, chronic stimulation of GPCRs, such as that which occurs during heart failure, leads to the overexpression of GRKs and maladaptive downregulation of GPCRs on the cell surface. We previously reported the discovery of potent and selective families of GRK inhibitors based on either the paroxetine or GSK180736A scaffold. A new inhibitor, CCG258747, which is based on paroxetine, demonstrates increased potency against the GRK2 subfamily and favorable pharmacokinetic parameters in mice. CCG258747 and the closely related compound CCG258208 also showed high selectivity for the GRK2 subfamily in a kinome panel of 104 kinases. We developed a cell-based assay to screen the ability of CCG258747 and 10 other inhibitors with different GRK subfamily selectivities and with either the paroxetine or GSK180736A scaffold to block internalization of the $\mu$-opioid receptor (MOR). CCG258747 showed the best efficacy in blocking MOR internalization among the compounds tested. Furthermore, we show that compounds based on paroxetine had much better cell permeability than those based on GSK180736A, which explains why GSK180736A-based inhibitors, although being potent in vitro, do not always show efficacy in cell-based assays. This study validates the paroxetine scaffold as the most effective for GRK inhibition in living cells, confirming that GRK2 predominantly drives internalization of MOR in the cell lines we tested and underscores the utility of high-resolution cell-based assays for assessment of compound efficacy.

\section{SIGNIFICANCE STATEMENT}

G protein-coupled receptor kinases (GRKs) are attractive targets for developing therapeutics for heart failure. We have synthesized a new GRK2 subfamily-selective inhibitor, CCG258747, which has nanomolar potency against GRK2 and excellent selectivity over other kinases. A live-cell receptor internalization assay was used to test the ability of GRK2 inhibitors to impart efficacy on a GRK-dependent process in cells. Our data indicate that CCG258747 blocked the internalization of the $\mu$-opioid receptor most efficaciously because it has the ability to cross cell membranes.

\section{Introduction}

G protein-coupled receptor (GPCR) kinases (GRKs) selectively phosphorylate activated GPCRs, thereby initiating receptor endocytosis and recycling events mediated by arrestins (Ferguson et al., 1996; Gurevich et al., 2012; Gurevich and

The work at University of Michigan was supported by the National Institutes of Health National Heart, Lung, and Blood Institute ([Grants HL071818 and HL122416] to J.J.G.T.); the National Institute of General Medical Sciences ([Grant GM117425] to M.A.P.); and the American Heart Association ([Grant 18POST33960047] to R.A.B.). Use of the Advanced Photon Source was supported by the U.S. Department of Energy, Office of Science, Office of Basic Energy Sciences, under Contract DE-AC02-06CH11357, and the use of Life Sciences Collaborative Access Team (LS-CAT) Sector 12 was supported by the Michigan Economic Development Corporation and Michigan Technology Tri-Corridor Grant 085P1000817.

https://doi.org/10.1124/mol.119.118661.

S This article has supplemental material available at molpharm. aspetjournals.org.
Gurevich, 2019). By terminating agonist-induced signaling, GRKs prevent prolonged activation of effector proteins and cellular stress, with the consequence of reducing receptor number at the cell surface (Rajagopal and Shenoy, 2018).

GRK-dependent regulation of activatable receptor populations has important physiologic and pathologic implications. The progression of heart failure is characterized by increased expression of GRK2 and GRK5, which are representatives of the two major GRK subfamilies, in cardiomyocytes and the concomitant reduction of $\beta_{1}$-adrenergic receptor (AR) density on the cell membrane (Rockman et al., 1998; Dzimiri et al., 2004; Salazar et al., 2007; Huang et al., 2011). GRK2 has also been shown to mediate desensitization of the $\mu$-opioid receptor (MOR), an important target for analgesia, and GRK2 and GRK5 have been shown to play roles in the development of tolerance

ABBREVIATIONS: AR, adrenergic receptor; DAMGO, [D-Ala ${ }^{2}, \mathrm{~N}-\mathrm{Me}-\mathrm{Phe}^{4}$, Gly-ol]-enkephalin; GPCR, G protein-coupled receptor; GRK, GPCR kinase; HEK, human embryonic kidney; LC-MS/MS, liquid chromatography with tandem mass spectrometry; MLM, mouse liver microsome; MOR, $\mu$-opioid receptor; OPRM1, opioid receptor $\mu$ 1; PDB, Protein Data Bank; PKA, protein kinase A; PRKD2, protein kinase D; pSer375, phosphorylated Ser375; ROCK1, Rho-associated coiled-coil-containing kinase 1; $\mathrm{SpH}$, superecliptic pHluorin. 
after chronic administration of the clinically relevant analgesic morphine (Fan et al., 2002; Quillinan et al., 2011; Glück et al., 2014; Mann et al., 2015). Thus, inhibition of GRK2 and GRK5 has been identified as a promising avenue for the development of new therapeutics for diseases such as heart failure, cardiac hypertrophy, and opioid addiction (Woodall et al., 2014, 2016; Mann et al., 2015; Quillinan et al., 2011).

Our laboratory previously conducted several screens to discover GRK2-selective inhibitors (Thal et al., 2012; Homan et al., 2015), revealing that both paroxetine and GSK180736A, a ROCK inhibitor, could selectively inhibit GRK2 subfamily members with low micromolar or high nanomolar potency, respectively. Later, a structure-based drug design approach was used to develop derivates based on the paroxetine and GSK180736A scaffolds with various extensions ("D-rings") (Fig. 1) (Waldschmidt et al., 2016, 2017). Additionally, we have discovered several compounds that potently inhibit both GRK2 and GRK5 (Bouley et al., 2017; Waldschmidt et al., 2018). Development of highly potent and selective GRK5 inhibitors remains a long-term goal.

Herein, we report a new GRK2 inhibitor, CCG258747, our most potent GRK2 inhibitor to date that retains good selectivity over GRK5, and describe its cocrystal structure with the GRK2-G $\beta \gamma$ complex at $2.4-\AA$ resolution. We show that this compound, along with another closely related inhibitor, CCG258208 (Waldschmidt et al., 2017), exhibit excellent selectivity over $>100$ other protein kinases. To evaluate our compounds in a cellular setting that would take into account their membrane permeability, we developed an assay to monitor how our compounds affect the internalization of the MOR. We showed that CCG258747 and CCG258208 are both able to effectively block the internalization of MOR in two cell lines, human embryonic kidney (HEK) 293 and U2OS, which express different levels of GRKs. These effects are not mediated through inhibition of MOR phosphorylation at Ser375, as validated by western blots, suggesting a mechanism at other sites of MOR phosphorylation. Furthermore, we confirmed that efficacy in this cell-based assay is strongly linked to cell permeability, a quality that will prove useful in selecting compounds for in vivo testing. In fact, poor permeability is a liability of most compounds based on the GSK180736A scaffold. The fact that GRK2-selective

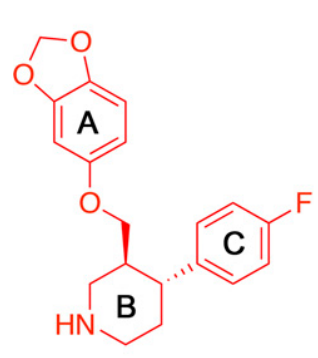

Paroxetine

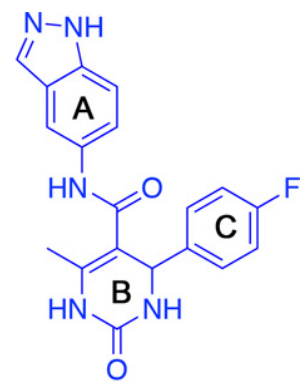

GSK180736A
Fig. 1. Structures of GRK inhibitor scaffolds. Rings are labeled according to the binding mode in the GRK2 active site. The A-ring binds in the adenine subsite and interacts with the hinge, the $\mathrm{B}$-ring binds in the ribose subsite, and the C-ring packs under the P-loop in the "polyphosphate subsite." The D-ring (not shown) referred to in the text is an orthosubstituent on the phenyl ring relative to the fluorine substituent (see Supplemental Fig. 1). compounds performed better or as well as pan-GRK inhibitors is consistent with GRK2 being the primary GRK responsible for MOR desensitization in living cells.

\section{Materials and Methods}

Synthesis. Synthetic procedures for CCG258747 are provided in the supplemental data. ${ }^{1} \mathrm{H}$ NMR spectra were taken in methanol- $\mathrm{d}_{4}$ at room temperature on a Varian Inova $400 \mathrm{MHz}$ instrument. Reported chemical shifts for the ${ }^{1} \mathrm{H}$ NMR spectra were recorded in parts per million on the $\delta$ scale from an internal standard of residual tetramethylsilane $(0 \mathrm{ppm})$. Mass spectrometry data were measured using a Waters Corporation Micromass LCT or Agilent6230 Q-TOF. High-performance liquid chromatography was used to determine purity of the compound on an Agilent 1100 series with an Agilent Zorbax Eclipse Plus-C18 column. A gradient of 10\%-90\% acetonitrile/ water over 6 minutes followed by $90 \%$ acetonitrile/water for 7 minutes was used with detection at $254 \mathrm{~nm}$. Purity of the final product was determined to be $98 \%$.

Kinase Activity Assays. Protein kinase A (PKA) and ROCK1 inhibition were assayed using the ADP-Glo Kinase Assay system (Promega, Madison, WI) as previously described (Homan et al., 2015). Compounds were tested against PKA in duplicate using an eight-point concentration range, and the experiment was repeated in triplicate on separate days. Compounds were screened at $10 \mu \mathrm{M}$ for ROCK1 inhibition in triplicate, the experiment repeated on three separate days, and the percent inhibition was calculated. A BMG Labtech PHERAstar imaging system was used to measure luminescence. Inhibition of GRK1, GRK2, and GRK5 was determined in $20 \mathrm{mM}$ HEPES (pH 7.0), $2 \mathrm{mM} \mathrm{MgCl}_{2}$, and $0.025 \% n$-dodecyl $\beta$-D-maltoside with $50 \mathrm{nM}$ of the respective GRK and $500 \mathrm{nM}$ tubulin. Kinetic reactions were initiated by the addition of $\left[\gamma_{-}{ }^{32} \mathrm{P}\right] \mathrm{ATP}(500 \mu \mathrm{Ci}, 5 \mu \mathrm{M})$, allowed to proceed for 8 minutes, and quenched by the addition of SDSloading buffer. Each compound was tested in duplicate using an eightpoint concentration range, and the experiment repeated on three separate days. Samples were then separated by SDS-PAGE, and gels were dried and exposed with a phosphorimaging screen. The images were then scanned with a Typhoon imager and quantified using ImageQuant, as previously described (Thal et al., 2012). Data were fit to a three-parameter dose-inhibitor response curve with a fixed Hill slope of 1 and the bottom constrained to 0 using GraphPad Prism. A maximum of two outliers were removed per individual data set using the automatic outlier rejection function, and in some cases an entire data set was excluded from the analysis.

Evaluation of Kinome Selectivity. CCG258208 and CCG258747 were tested against 104 human kinases at $1 \mu \mathrm{M}$ using the scanELECT kinase selectivity and profiling assay panel, which was performed by the KINOMEscan division of Eurofins DiscoverX (San Diego, CA) (Fabian et al., 2005). GRK1, GRK2, GRK3, GRK4, GRK7, protein kinase D (PRKD2), and ROCK1 were added to the screen because they were not included in the standard scanELECT kinase assay panel. ROCK1 was chosen because the GSK180736A scaffold was originally designed as a ROCK1 inhibitor, whereas PRKD2 was chosen to provide an additional example of an AGC kinase, a kinase family in which we expected most of our off-target activity to occur.

Mouse Liver Microsome Assays. Metabolic stability was determined using CD-1 mouse liver microsomes. Reactions consisted of $1 \mu \mathrm{M}$ compound, $0.5 \mathrm{mg} / \mathrm{ml}$ microsomes, and $1.7 \mathrm{mM} \mathrm{NADPH}$ in $0.1 \mathrm{M}$ phosphate buffer ( $\mathrm{pH} 7.4$ ) supplemented with $3.3 \mathrm{mM} \mathrm{MgCl}_{2}$ and incubated at $37^{\circ} \mathrm{C}$. Aliquots of $40 \mu \mathrm{l}$ were taken at $0,5,10,15,30,45$, and 60 minutes and quenched in three volumes of cold acetonitrile containing $100 \mathrm{ng} / \mathrm{ml}$ internal standard. Samples were centrifuged at $15,000 \mathrm{rpm}$ for 10 minutes, and the supernatant was analyzed by LC-MS/MS.

Mouse Pharmacokinetic Studies. All animal experiments were approved and conducted in accordance with standards set by the University of Michigan Committee on Use and Care of Animals and 
Unit for Laboratory Animal Medicine. Preliminary pharmacokinetics of CCG258748 were determined in female CD-1 mice after intraperitoneal injection at $10 \mathrm{mg} / \mathrm{kg}$. The compound was dissolved in $20 \%(\mathrm{v} / \mathrm{v})$ DMSO, 50\% (v/v) polyethylene glycol-400, and 30\% (v/v) PBS. Blood samples of $50 \mu \mathrm{l}$ were collected at $0.5,2,4$, and 7 hours and centrifuged at $3500 \mathrm{rpm}$ for 10 minutes, and the plasma were frozen at $-80^{\circ} \mathrm{C}$ for later analysis. Plasma compound concentrations were quantified using LC-MS/MS. The LC-MS/MS method consisted of a Shimadzu high-performance liquid chromatography system with a Waters XbridgeC18 column $(5 \mathrm{~cm} \times 2.1 \mathrm{~mm}, 3.5 \mu \mathrm{m})$ for chromatographic separation of the compound. An AB Sciex QTrap 4500 mass spectrometer equipped with an electrospray ionization source (ABI-Sciex, Toronto, Canada) in the positive-ion multiple reaction-monitoring mode for detection. All pharmacokinetic parameters were calculated by noncompartmental methods using WinNonLin software, version 3.2 (Pharsight Corporation, Mountain View, CA).

Protein Expression and Purification. Human GRK2 S670A with a C-terminal hexahistidine tag was expressed in High-Five cells using the Bac-to-Bac insect cell expression system (Life Technologies, Carlsbad, CA). Cells were harvested 48 hours postinfection and lysed. GRK2 was purified from the clarified lysate as described previously for GRK1 using nickel-nitrilotriacetic acid affinity and cation-exchange chromatography (Singh et al., 2008). Fractions containing GRK2 were pooled and further purified on a Sephadex 200 column into $20 \mathrm{mM}$ HEPES ( $\mathrm{pH} 7.5$ ), $100 \mathrm{mM} \mathrm{NaCl}$, and $1 \mathrm{mM}$ dithiothreitol. Soluble human $\mathrm{G} \beta_{1} \gamma_{2}$ (C68S mutant) containing an $\mathrm{N}$-terminal hexahistidine tag on the $\mathrm{G} \beta_{1}$ unit was expressed using a dual-promoter insect cell expression vector in High-Five cells. The cells were harvested 48 hours postinfection and lysed. G $\beta_{1} \gamma_{2}$ was purified from the clarified lysate as described previously using nickel-nitrilotriacetic acid affinity and anion-exchange chromatography (Kozasa, 2004). Fractions containing $\mathrm{G} \beta_{1} \gamma_{2}$ were pooled and further purified on a Sephadex 200 column into $20 \mathrm{mM}$ HEPES (pH 8.0), $100 \mathrm{mM} \mathrm{NaCl}$, and $1 \mathrm{mM}$ dithiothreitol.

Crystal Structure Determination. Purified GRK2 (S670A) and soluble $\mathrm{G} \beta_{1} \gamma_{2}(\mathrm{C} 68 \mathrm{~S})$ were mixed in a 1:1.2-M ratio with a final protein concentration of approximately $10 \mathrm{mg} / \mathrm{ml}$. CCG258747 $(500 \mu \mathrm{M})$ and $\mathrm{MgCl}_{2}(2 \mathrm{mM})$ were added to the protein mixture and allowed to incubate on ice for 30 minutes prior to filtration through a $0.2-\mu \mathrm{m}$ Nanosep centrifugal device (Pall Laboratory, Port Washington, NY). The inhibitor complex was crystallized as previously described by hanging drop vapor diffusion at $4^{\circ} \mathrm{C}$ with drops consisting of $0.8 \mu \mathrm{l}$ protein and $0.8 \mu \mathrm{l}$ reservoir solution, which consisted of $50 \mathrm{mM}$ 4-morpholineethanesulfonic acid $(\mathrm{pH}$ 6.0), $1.1 \mathrm{M} \mathrm{NaCl}$, and $6 \%$ polyethylene glycol-3350 (Thal et al., 2011, 2012). Crystals generally appeared after 2 to 3 days and grew for 1 to 2 weeks. Crystals were harvested in a cryoprotectant solution consisting of the reservoir solution supplemented with $25 \%$ ethylene glycol and $500 \mu \mathrm{M}$ inhibitor before being flash frozen in liquid nitrogen. Diffraction data were collected on the Life Sciences Collaborative Access Team beamline 21-ID-D at a wavelength of $1.0332 \AA$. Data integration and scaling were performed with Diffraction Integration for Advanced Light Sources (Gildea et al., 2014). The structures were solved using Phaser (McCoy et al., 2007) with Protein Data Bank (PDB) ID 4PNK as the search model. Reciprocal-space refinement was performed with PHENIX (Afonine et al., 2012) and alternated with local real-space refinement and model building using Coot (Emsley and Cowtan, 2004). Crystallographic data collection and refinement statistics are listed in Supplemental Table 1. The final model was validated using MolProbity (Chen et al., 2010) prior to deposition in the PDB under accession code $6 \mathrm{U} 7 \mathrm{C}$.

Cell Culture and DNA Constructs. Superecliptic pHluorin (SpH)-MORand MOR N-terminally tagged with the $\mathrm{pH}$-sensitive GFP SpH (Sankaranarayanan et al., 2000)were generated as previously described (Soohoo and Puthenveedu 2013). Stable cell lines expressing this construct were generated using HEK293 cells (CRL-1573) and U2OS cells (HTB-96) obtained from American Type Culture Collection cultured in $400 \mu \mathrm{g} / \mathrm{ml}$ G418 (Thermo
Fisher Scientific, Waltham, MA) (Soohoo and Puthenveedu, 2013). Once stable expression was obtained, cells were cultured in either Dulbecco's Modified Essential Medium High Glucose for HEK293 (Hyclone, Logan, UT) or McCoy's 5A Modified Medium for U2OS (Gibco, Gaithersbug, MD) supplemented with 10\% FBS (Gibco) without antibiotic.

Receptor Internalization Assays. HEK293 or U2OS cells stably expressing $\mathrm{SpH}-\mathrm{MOR}$ were plated at high density on 25-mm \#1.5 coverslips (Electron Microscopy Sciences, Hatfield, PA) and allowed to grow to confluency for 2-4 days. Confluent coverslips were pretreated with DMSO or GRK inhibitor for 15 minutes before being transferred to a live imaging chamber where they were immersed in Leibovitz $\mathrm{CO}_{2}$-independent media with $1 \% \mathrm{FBS}$ (Gibco) containing additional DMSO or inhibitor. Fluorescence was collected using a CSU-X1 spinning disk confocal unit (Yokogawa, Sugar Land, TX), a $20 \times$ $0.75 \mathrm{NA}$ objective on a Ti-E inverted microscope (Nikon Instruments, Melville, NY), excitation with a 488-nm laser line (Andor, Belfast, Ireland), a 525/30 emission filter (Semrock, Rochester, NY), and an iXon 897 EMCCD camera (Andor). The microscope stage enclosure was kept at $37^{\circ} \mathrm{C}$. Twenty fields per coverslip were selected, and a baseline fluorescence was collected over four frames at 30-second intervals in each field. After baseline, cells were treated with buffer for no-treatment control or [D-Ala ${ }^{2}, N-\mathrm{Me}^{-P_{h}{ }^{4}}$, Gly-ol]-enkephalin (DAMGO) (Sigma Aldrich, St. Louis, MO) at a final concentration of $10 \mu \mathrm{M}$, and images were collected every 30 seconds for an additional 10 minutes. Images were analyzed using Fiji (Schindelin et al., 2012). Images were thresholded to only include pixels with intensity above 200 counts (absorbance units), which was just above the camera background of 120 counts. Receptor internalization was subsequently calculated as $F_{n} / F_{B}$, in which $F_{n}$ is the thresholded integrated fluorescence intensity of the frame at timepoint $n$, and $\mathrm{F}_{\mathrm{B}}$ is the thresholded and averaged integrated fluorescence intensity of the first four recorded frames before DAMGO addition. These calculations were automated using an open source ImageJ script (Weinberg, 2019).

Cell Permeability Determination. Compounds were submitted to Pion Inc. (Billerica, MA) for cell permeability determination using the Double-Sink parallel artificial membrane permeation assay system (Kansy et al., 1998; Avdeef, 2001). Propranolol and atenolol were used as positive and negative controls, respectively.

Western Blot Analysis. HEK293 or U2OS cells stably expressing SpH-MOR were plated in growth medium (Dulbecco's modified Eagle's medium $+10 \%$ FBS) at a density of 300,000 cells/well in a 12 -well plate and allowed to grow to full confluency ( 2 to 3 days). Cells were treated with DMSO or inhibitor at $20 \mu \mathrm{M}$ for 20 minutes, which was followed by 30 minutes of $10 \mu \mathrm{M}$ DAMGO treatment. Cells were then lysed on ice in isotonic lysis buffer [2\% SDS, $60 \mathrm{mM}$ Tris ( $\mathrm{pH} \mathrm{6.8),} \mathrm{Pierce}$ Protease and Phosphotase inhibitors] and sonicated. Protein concentration was quantified using Pierce bicinchoninic acid protein estimation. Equal amounts of lysate from each condition were loaded on a $7.5 \%$ SDS-PAGE gel, and after separation they were transferred overnight to a nitrocellulose membrane. Membranes were blocked in Tris-buffered saline/Tween 20 with $5 \%$ bovine serum albumin for 1 hour and then incubated with 1:1000 anti-pSer375 OPRM1 antibody (PA5-17698; Thermo Fisher) overnight at $4^{\circ} \mathrm{C}$. Membranes were developed using horseradish peroxidase-conjugated secondary antibodies (Biorad) and SuperSignal Femto ECL substrate (Thermo) and imaged using an iBright CL1000 Imaging System (Thermo). Membranes were stripped for 30 minutes at room temperature using Restore stripping buffer (Thermo) and subsequently reblocked for 1 hour in Tris-buffered saline/Tween 20 with 5\% powdered milk. Membranes were incubated with 1:2000 antiOPRM1 antibody (ab134054; Abcam) overnight, and development was repeated as above. Displayed blot is representative of two biologic replicates. Band densitometry was calculated for phospho-MOR and total MOR bands using iBright Analysis Software (Thermo). PhosphoMOR was normalized to total MOR for each sample, and then all samples were normalized to their paired DMSO treatment control 
condition. Differences were evaluated using a one-way repeated measures ANOVA (GraphPad Prism).

\section{Results}

Kinase Activity Assays. Our previously reported CCG258208 paroxetine analog with a pyrazole as its D-ring substituent had an $\mathrm{IC}_{50}$ of $30 \mathrm{nM}$ for GRK2 with 240 -fold selectivity over GRK5 (Waldschmidt et al., 2017). The indazole analog CCG258747 reported here exhibited a further increase in GRK2 potency $\left(\mathrm{IC}_{50}=18 \mathrm{nM}\right)$ while retaining 83-fold selectivity over GRK5 (Supplemental Fig. 1). Additionally, CCG258747 was more selective against GRK1 and PKA and showed little inhibition against ROCK1 at $10-\mu \mathrm{M}$ concentration (Table 1).

Evaluation of Kinome Selectivity. Off-target activity can lead to undesired side effects because kinases play key roles in many cellular processes (Fabian et al., 2005; Yang et al., 2010; Davis et al., 2011). To more broadly assess the kinome-wide selectivity of our lead GRK2-selective paroxetine derivatives, we submitted CCG258208 or CCG258747 for evaluation at $1 \mu \mathrm{M}$ in the scanELECT screen (DiscoverX) consisting of a panel of 104 kinases with the addition of GRK1, GRK2, GRK3, GRK4, GRK7, PRKD2, and ROCK1 (Fig. 2). The assay evaluated thermodynamic inhibitorbinding affinity and reports a remaining percent control activity. Compounds are assigned a selectivity score, $\mathrm{S}(35)$, which is a ratio of the number of hits exhibiting less than $35 \%$ of the activity of control over the number of assays performed. The $\mathrm{S}(35)$ selectivity scores for CCG258208 and CCG258747 were both 0.02 , indicating that they are highly selective inhibitors. For CCG258208 and CCG258747 the percent control activities for GRK2 and GRK3 were $0.7 \%$ and $0.0 \%$ and $2.5 \%$ and $2.1 \%$, respectively. The next highest activity for both compounds was against ROCK1 (50\% and $47 \%$, respectively). Only five other kinases with a percent of control activity $\leq 70 \%$ were observed for CCG258747, and
13 were observed for CCG258208 (Supplemental Table 2). Thus, although CCG258747 had relatively higher off-target potency against GRK1 and GRK4 (each with $67 \%$ percent control), it seemed to have less overall off-target kinase activity than CCG258208.

Preliminary Pharmacokinetic Studies in Mice. The stability of CCG258747 toward incubation with mouse liver microsomes (MLMs) was evaluated to guide selection of analogs with favorable pharmacokinetic properties (Table 2). As previously reported, our lead compound, paroxetine, had a $t_{1 / 2}$ of 24 minutes, and the pyrazole analog, CCG258208, had a $t_{1 / 2}$ of 7.0 minutes in the MLM assay (Waldschmidt et al., 2017). We had previously found that the polar carboxamidelinked motif on the paroxetine core exhibited metabolic instability. This instability may be the result of the heterocyclic nitrogens coordinating to the heme of cytochrome P450. Favorably, the bulkier indazole carboxamide CCG258747 exhibited a substantially higher $t_{1 / 2}$ in MLMs of 40 minutes. Thus, the added bulk to the heterocycle may be blocking its ability to coordinate to heme relative to the pyrazole group of CCG258208.

Compound CCG258747 was further evaluated in an abbreviated in vivo pharmacokinetic study in mice (Table 2). Plasma samples were collected at four different time points over 7 hours, and drug levels in plasma were quantified after intraperitoneal injection into CD-1 mice at a dose of $10 \mathrm{mg} / \mathrm{kg}$. After 30 minutes, CCG258747 had a concentration of 1520 $\mathrm{nM}$, whereas CCG258208 was $2710 \mathrm{nM}$ at 30 minutes (Waldschmidt et al., 2017). However, CCG258747 maintained a slightly lower curve of clearance relative to CCG258208. The observed area-under-the-curve (AUC) for CCG258747 was also lower than that of CCG258208 (4970 vs. 5970 hours.nM). As with CCG258208, CCG258747 was also able to maintain total plasma drug levels after single intraperitoneal administration that exceeded the GRK2 $\mathrm{IC}_{50}$ for at least 7 hours, making it a suitable candidate for future in vivo efficacy studies in mice.

TABLE 1

Kinase inhibitory activity of CCG258208 and CCG258747

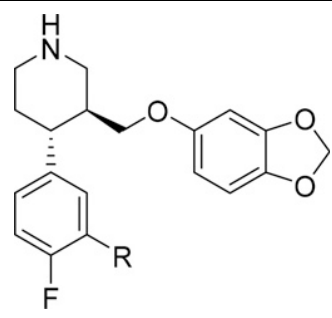

\begin{tabular}{|c|c|c|c|c|c|c|}
\hline $\mathrm{R}$ & Compound & 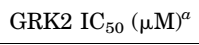 & $\operatorname{GRK1} \mathrm{IC}_{50}(\mu \mathrm{M})^{a}$ & 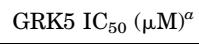 & $\mathrm{PKA} \mathrm{IC}_{50}(\mu \mathrm{M})^{a}$ & $\operatorname{ROCK1}^{b}(\%)$ \\
\hline $\mathrm{H}$ & Paroxetine & $1.4 \pm 1$ & $>100$ & $>100$ & $>100$ & 10 \\
\hline & 258208 & $0.030 \pm 0.001$ & $87 \pm 30$ & $7.1 \pm 0.7$ & $>100$ & 9 \\
\hline & 258747 & $0.018 \pm 0.006$ & $9.3 \pm 3$ & $1.5 \pm 0.5$ & $>100$ & 27 \\
\hline
\end{tabular}

${ }^{a} \mathrm{All} \mathrm{IC}_{50}$ measurements are an average of three separate experiments run in duplicate. Errors shown represent error of the mean

${ }^{b}$ Percent inhibition at $10 \mu \mathrm{M}$ inhibitor concentration. IC $_{50}$ data for paroxetine and CCG258208 are reproduced from Waldschmidt et al. (2017) for comparison. 
A
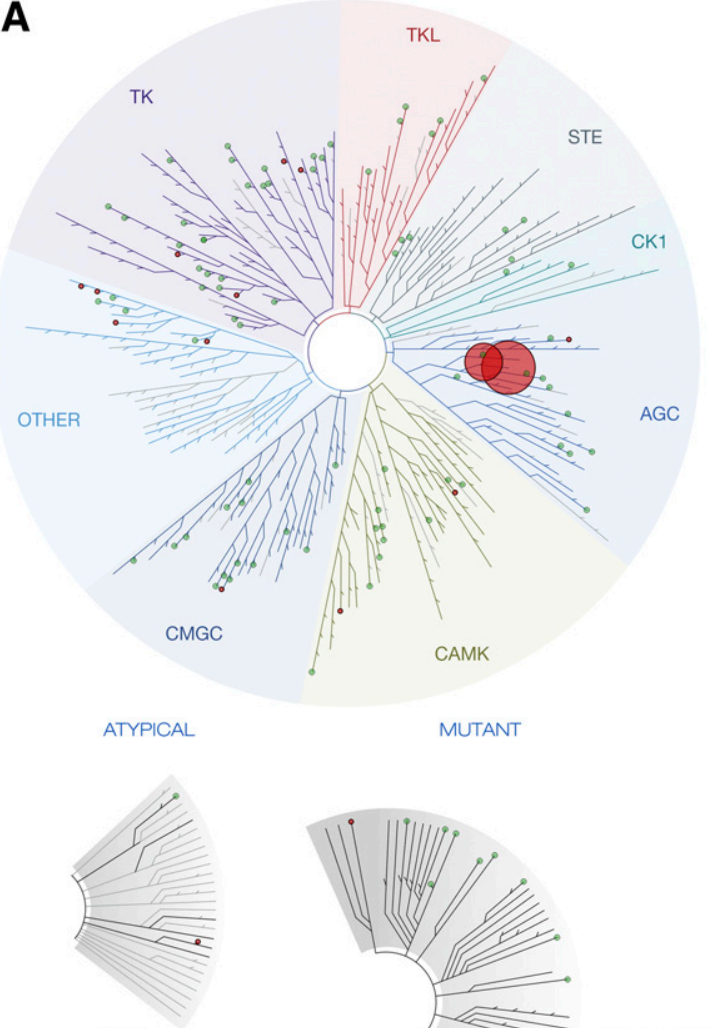

LIPID

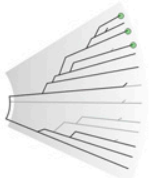

PATHOGEN

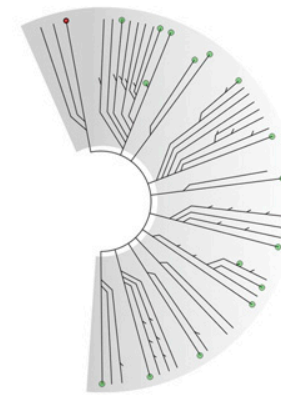

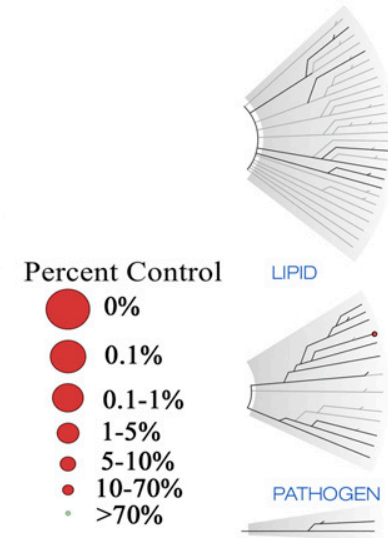

B
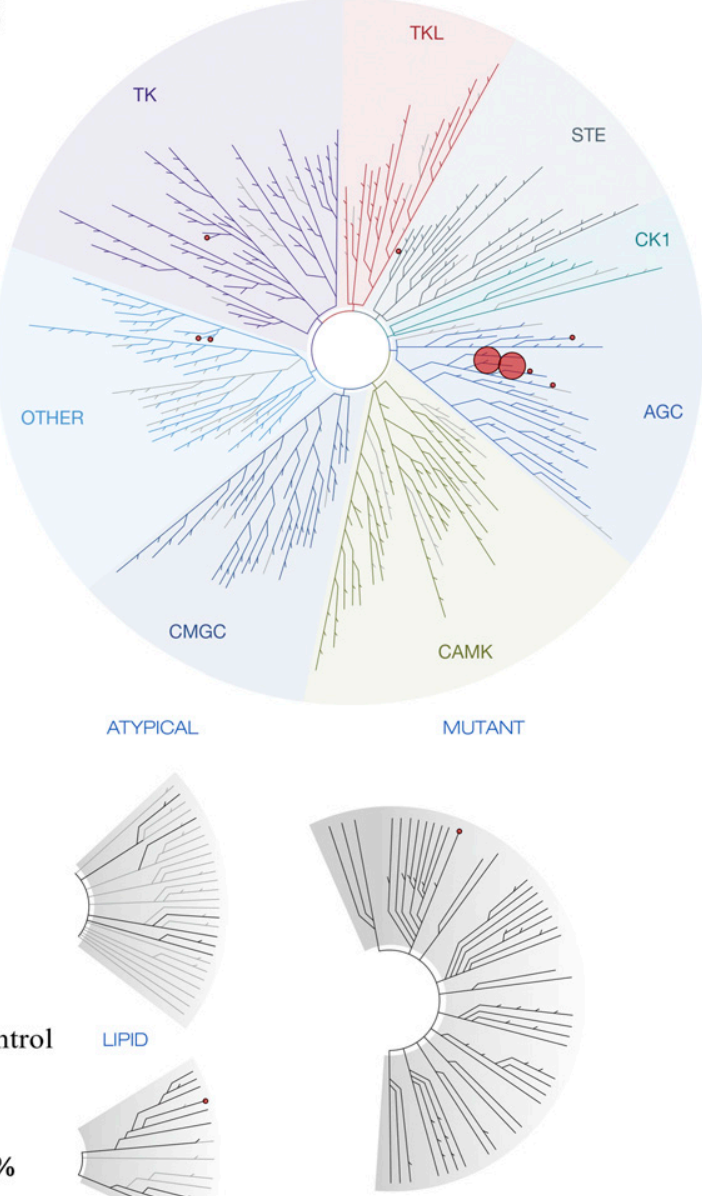

Fig. 2. Kinome selectivity of CCG258208 and CCG258747 at $1 \mu \mathrm{M}$. Kinome scan data for (A) CCG258208 and (B) CCG258747. Each kinase subfamily is highlighted in the kinome. Under the AGC kinase subfamily, two large red dots show the reported percent control inhibition for GRK2 and GRK3. Other kinases with a percent activity between $10 \%$ and $70 \%$ are shown as small red dots. All other kinases with a percent activity greater than $70 \%$ are represented with green dots.ACG, protein A, G, and C families; CMGC, CDK, MAPK, GSK3, and CLK families; CAMK, calmodulin/calcium regulated kinases; CK1, casein kinase 1; STE, homologs of STE7, STE11, STE20 yeast genes; TK, tyrosine kinase family; TKL, tyrosine kinase-like family.

Crystallography. The indazole analog CCG258747 crystallized in complex with GRK2-G $\beta \gamma$ (Fig. 3A) in space group $\mathrm{C} 222_{1}$, a form that had not been previously observed with other paroxetine derivatives and diffracted to a resolution of $2.44 \AA$ A. This crystal form is, however, analogous to those obtained with our previously reported GSK180736A-derived (Waldschmidt et al., 2016, 2018) and indazole-paroxetine series compounds (Bouley et al., 2017). As with other paroxetine analogs, the benzodioxole of CCG258747 forms hydrogen bonds with backbone atoms of Met274 and Asp272 in the kinase hinge. The central piperidine nitrogen makes a hydrogen bond with the carbonyl of Ala321 in the ribose subsite, and the fluorophenyl group packs under the P-loop. As observed for CCG258208 (PDB ID: 5UKM), the indazole nitrogens of CCG258747 form hydrogen bonds with Glu239 and Lys220 in the hydrophobic subsite (Fig. 3A). The phenyl of the indazole ring packs in a manner similar to what is seen with CCG211998 (PDB ID: 5UKK), making edge-to-face $\pi$-stacking interactions with the side chain of Phe 202 at the tip of the P-loop. The indazole pushes the P-loop, $\alpha \mathrm{B}$ helix, $\alpha \mathrm{B}-\alpha \mathrm{C}$ loop, and $\alpha \mathrm{C}$ helix of the kinase domain small lobe a maximum of $2.4 \AA$ (C $\alpha$ of Thr234) outward from the active

TABLE 2

In vivo exposure after intraperitoneal administration to mice CD-1 mice were injected intraperitoneally with a single indicated dose. The data shown are mean values from three mice at each time point.

\begin{tabular}{lccccc}
\hline & \multicolumn{3}{c}{ Compound Concentration in Plasma (nM) } & \multirow{2}{*}{ AUC obs ${ }_{0-7}^{\text {ob }}(\mathrm{h} \cdot \mathrm{nM})$} \\
\cline { 2 - 5 } Compound (dose) & $30 \mathrm{~min}$ & $2 \mathrm{~h}$ & $4 \mathrm{~h}$ & $7 \mathrm{~h}$ & \\
\hline CCG258208 $(10 \mathrm{mg} / \mathrm{kg})$ & 2710 & 1440 & 270 & 430 & 5970 \\
CCG258747 $(10 \mathrm{mg} / \mathrm{kg})$ & 1530 & 1150 & 470 & 170 & 4970 \\
\hline
\end{tabular}

AUC, area under the curve. 


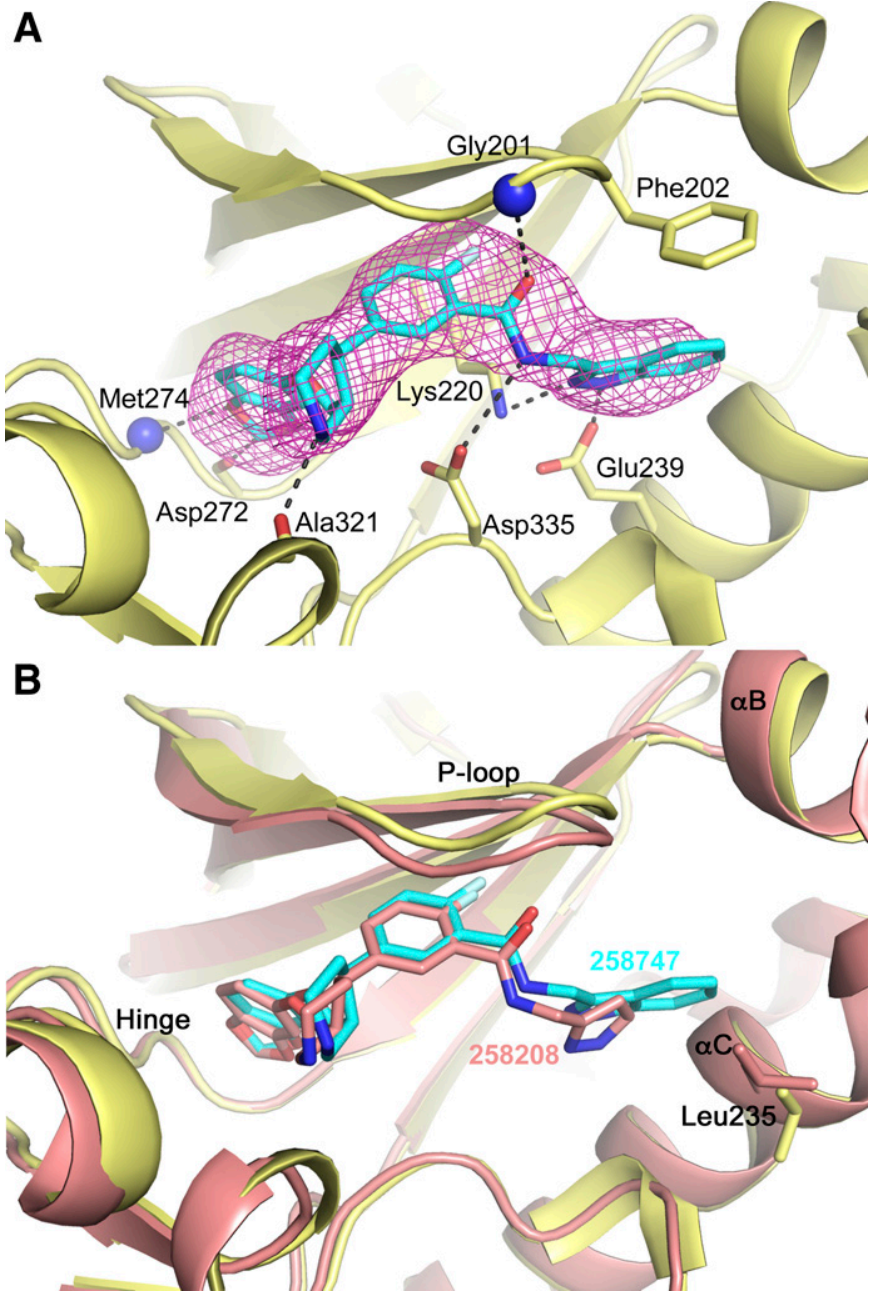

Fig. 3. Structure of GRK2-G $\beta \gamma$ in complex with CCG258747. (A) GRK2G $\beta \gamma$.CCG258747 crystal structure. GRK2 is in light yellow, and CCG258747 is colored with cyan carbons. Electron density from an $\left|F_{\mathrm{o}}\right|$ - $\left|F_{\mathrm{c}}\right|$ omit map is contoured at $3.0 \sigma$ and shown as magenta mesh. Hydrogen bonds are indicated by dashed black lines. (B) Overlay of the GRK2-G $\beta \gamma$.CCG258208 (salmon cartoon and carbons) and GRK2G $\beta \gamma$.CCG258747 (light yellow cartoon and cyan carbons) atomic models.

site to form a larger pocket. The active-site tether loop, which passes over the active site, has lower temperature factors in the GRK2-G $\beta \gamma \cdot \mathbf{C C G 2 5 8 7 4 7}$ complex compared with CCG258208, with residues 480-482 making direct contacts with the piperidine ring of the bound inhibitor. The overall root-mean-square deviation between the CCG258747 and CCG258208 complexes was $0.5 \AA$ for all backbone atoms.

Receptor Internalization Assays. We next tested a series of our compounds including CCG258747 and CCG258208 (Supplemental Fig. 2) for their ability to prevent GPCR internalization using live-cell confocal microscopy, wherein we monitored the GRK-dependent internalization of an activated GPCR in real time using an $\mathrm{SpH}$ tag, as previously described (Vistein and Puthenveedu, 2013). Fluorescence of the $\mathrm{SpH}$-tagged receptor is quenched in intracellular compartments because of their acidic $\mathrm{pH}$ and the $\mathrm{pH}$ dependence of this tag. Thus, the fluorescence intensity can be directly correlated to the total levels of receptors at the cell surface, existing at an equilibrium between receptor internalization and receptor recycling. MOR was used as a model system because the internalization of MOR has been reported to be primarily dependent on GRK2/3 and only partially dependent on GRK5/6 (Just et al., 2013; Miess et al., 2018). Robust internalization of MOR is observed with the peptide agonist DAMGO, which leads to higher phosphorylation of Thr376 and Thr379, which are sites dependent on GRK2/3 activity (Just et al., 2013). The multisite phosphorylation patterns in MOR have also been shown to occur sequentially after initial phosphorylation of Ser375 (Just et al., 2013). Thus, we predicted that potent inhibitors of GRK2 with favorable cell permeability would significantly reduce internalization of MOR. We also predicted that inhibitors with both potency against both GRK5 and GRK2 might inhibit internalization to a greater extent given their ability to reduce phosphorylation by multiple GRK subfamilies.

Inhibitors selected for the screen featured components found in either the original paroxetine or GSK180736A chemical scaffolds (Supplemental Fig. 2) and were tested at $20 \mu \mathrm{M}$ on HEK293 and U2OS cell lines stably expressing the $\mathrm{SpH}-\mathrm{MOR}$ construct. Compounds were tested at $20 \mu \mathrm{M}$ because this was the minimum concentration for CCG258747 and CCG258208 that demonstrated robust efficacy in blocking receptor internalization in HEK293 cells (Supplemental Fig. 3). Paroxetine at $50 \mu \mathrm{M}$ was included as a control. HEK293 cells endogenously express GRK2, GRK3, GRK5, and GRK6, whereas U2OS cells express GRK2, GRK3, and GRK5 (Violin et al., 2006). Similar results were obtained for the compounds in both cell lines, with the caveat that the overall efficacy was higher in U2OS cells (Supplemental Fig. 4). CCG258747 was the most effective at blocking MOR internalization in both cell lines, whereas CCG258208 was the second most effective (Fig. 4). Although several of the inhibitors tested were also potent inhibitors of GRK5 $\left(\mathrm{IC}_{50}<1 \mu \mathrm{M}\right.$ ) (Table 3), they did not seem to provide any advantage in blocking the internalization of MOR in this assay in either cell line. However, the compounds with a piperidine as their B-ring (based on the paroxetine scaffold) demonstrated much better efficacy in this cell-based assay than those with a dihydropyrimidine B-ring (based on the GSK180736A scaffold). GRK2 potency overall seemed to drive efficacy in this assay with the notable exception of CCG258748 (GRK2 $\mathrm{IC}_{50}=8 \mathrm{nM}$ ), which showed no efficacy in HEK293 cells and only moderate efficacy in U2OS cells (Supplemental Fig. 4).

Cell Permeability Determination. We hypothesized that cell permeability was the primary reason we saw differences between compounds featuring paroxetine- or GSK-based B-rings. In order for a compound to show efficacy in blocking the internalization of MOR, they would have to cross the cell membrane and be present in the cytosol in sufficient concentrations to inhibit GRKs. Several compounds, such as CCG224406 and CCG215022, did not display efficacy against MOR internalization despite being potent GRK2 inhibitors ( $\mathrm{IC}_{50}$ values of 130 and $150 \mathrm{nM}$, respectively). We submitted eight representative compounds as well as paroxetine to Pion to determine cell permeability using the parallel artificial membrane permeation assay system (Table 3). Unsurprisingly, paroxetine demonstrated excellent membrane permeability, even outperforming the positive control propranolol. The two compounds tested with dihydropyrimidine cores (CCG215022 and CCG257142) showed very poor permeability across the membrane and also poor membrane retention. Several paroxetine-based compounds showed 
A

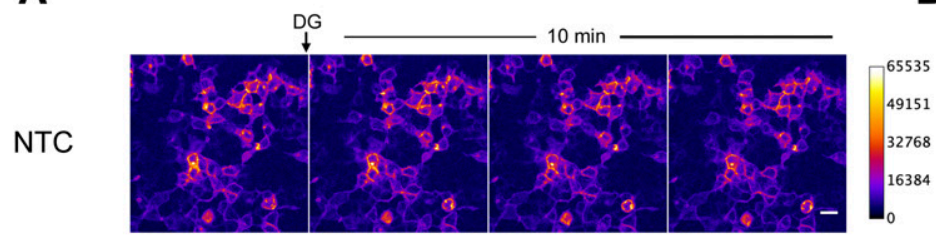

DG
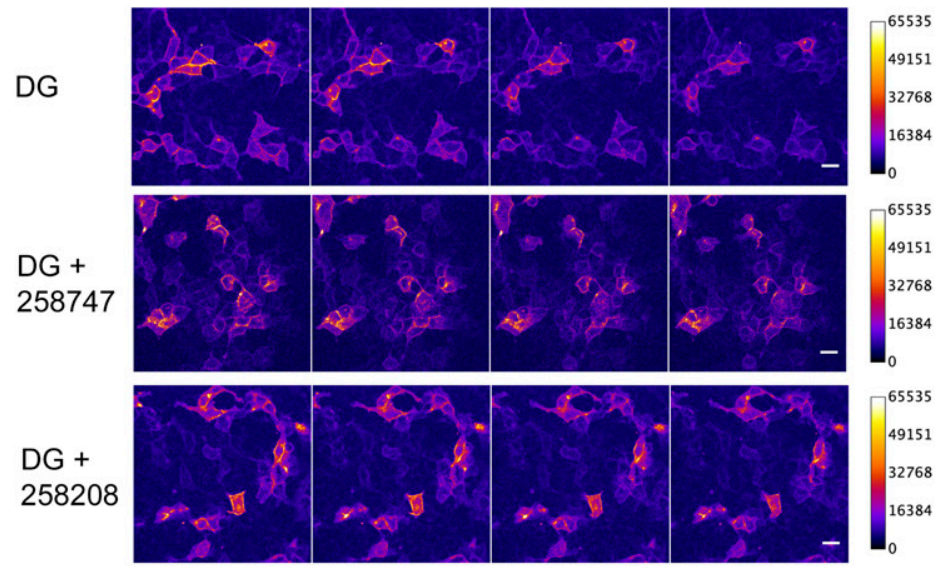

C

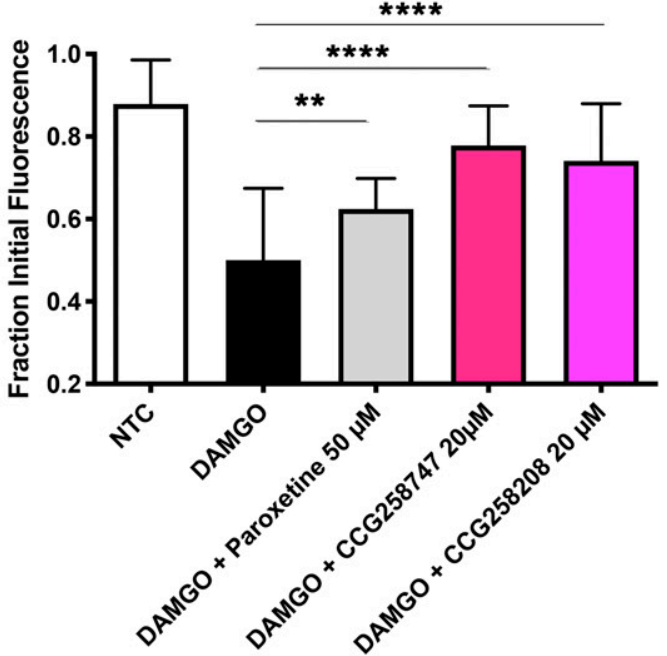

B
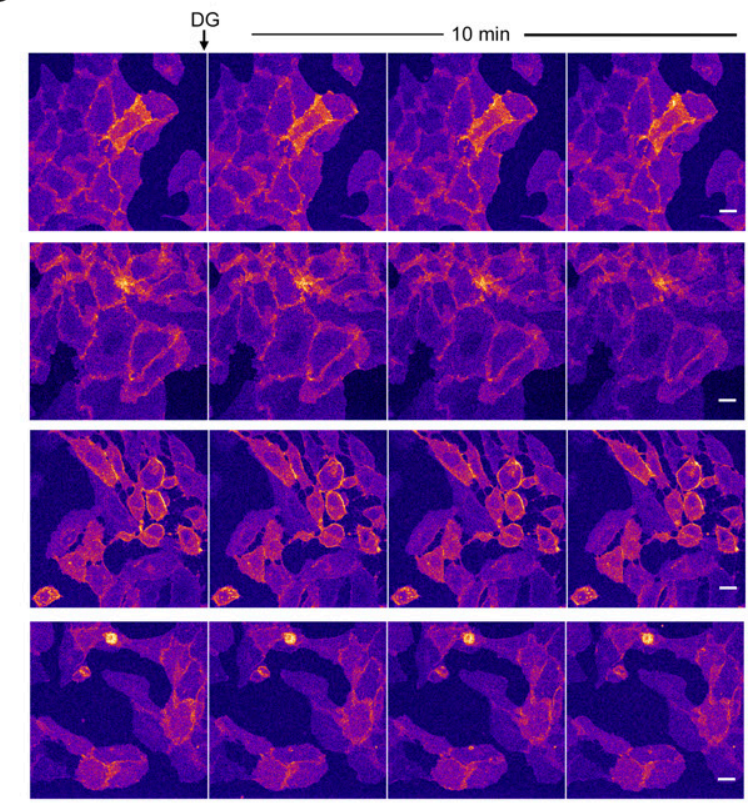

D

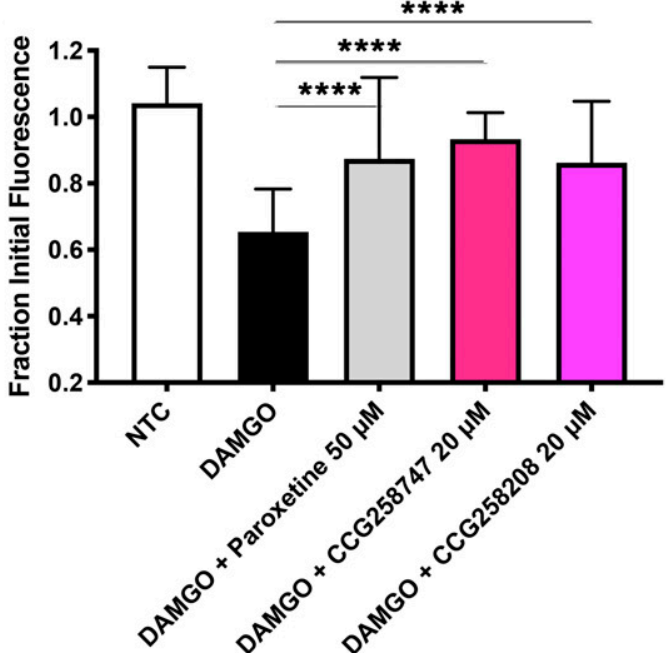

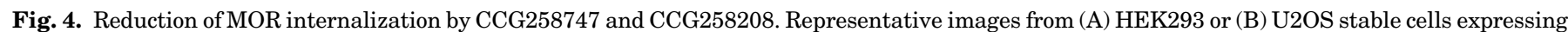

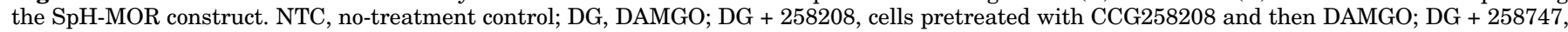

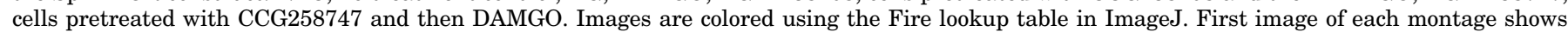

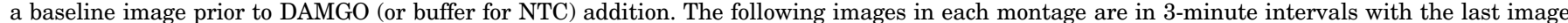

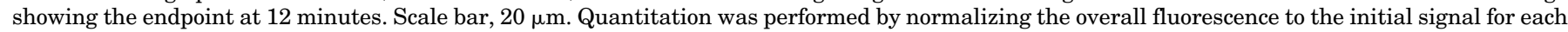

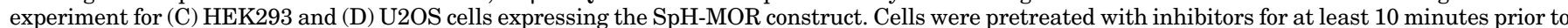

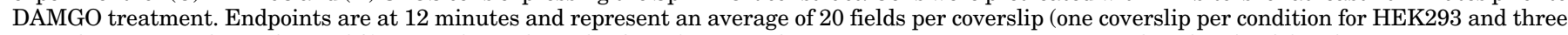

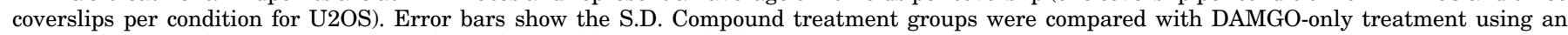
unpaired $t$ test to demonstrate statistical significance; $* * P<0.01 ; * * * * P<0.0001$

significant permeability $\left(>1.0 \times 10^{-6} \mathrm{~cm} / \mathrm{s}\right)$ and membrane retention ( $>25 \%$ ). CCG258748 was the only paroxetine-based compound that had both poor permeability and membrane retention, which could help explain its lack of efficacy in HEK293 compared with U2OS cells. CCG258747 had similar permeability to CCG258208 but had greater retention in the membrane, likely due to its greater hydrophobicity. The paroxetine derivatives with the best membrane permeability were CCG224061 and CCG258022, which both block lack a D-ring substituent and differ structurally from one another by only a single fluorine substituent (Supplemental Fig. 2). Additionally, CCG224061 and CCG258022 differ in their hinge-binding moiety (A ring), which suggests that the major driver for solubility and permeability is the identity of the B-ring (piperidine vs. dihydropyrimidine).

Western Blot Analysis. To test how CCG258747 and CCG258208 affect the phosphorylation of MOR in our assay system, we blotted for MOR using an antibody selective for pSer375, which is the only commercially available phosphositespecific antibody for MOR. Upon DAMGO treatment we observed an increase in pSer375-MOR for both HEK293 and U2OS stable cells, as expected (Fig. 5). In the presence of CCG258747 but not CCG258208 phosphorylation of Ser375 was reduced, although not in a statistically significant manner (Supplemental Fig. 5). This suggests the possibility that these compounds instead exert their effect on MOR internalization 
TABLE 3

GRK inhibition, cell permeability, and membrane retention of key inhibitors

Values are averages of $n=4$ at $\mathrm{pH}$ of 7.4. Error for $\mathrm{P}_{\mathrm{e}}$ and \%R are shown as S.D. GRK2 and GRK5 $\mathrm{IC}_{50}$ values are reproduced here for ease of comparison and represent an average of three separate experiments run in duplicate. Corresponding references are provided for previously published data.

\begin{tabular}{|c|c|c|c|c|c|}
\hline Compound \# & $\operatorname{Avg} P_{e}\left(\times 10^{-6} \mathrm{~cm} / \mathrm{s}\right)$ & Avg \%R & GRK2 IC $50(\mu \mathrm{M})$ & GRK5 IC $50(\mu \mathrm{M})$ & Reference for $\mathrm{IC}_{50}$ Data \\
\hline Paroxetine & $92 \pm 7$ & $34 \pm 2$ & 1.4 & $>100$ & Waldschmidt et al., 2017 \\
\hline 258748 & $<0.3$ & $8 \pm 1$ & 0.008 & 0.24 & Bouley et al., 2017 \\
\hline 258747 & $1.2 \pm 0.1$ & $78 \pm 1$ & 0.018 & 1.5 & Table 1 \\
\hline 258208 (14as) & $1.4 \pm 0.7$ & $46 \pm 1$ & 0.03 & 7.1 & Waldschmidt et al., 2017 \\
\hline 224061 & $23 \pm 1$ & $66 \pm 1$ & 0.066 & 1.3 & Bouley et al., 2017 \\
\hline 257284 & $<0.5$ & $29 \pm 2$ & 0.10 & 0.50 & Bouley et al., 2017 \\
\hline 258002 & $18 \pm 3$ & $69 \pm 3$ & 0.14 & 3.7 & Bouley et al., 2017 \\
\hline GSK180736A & ND & ND & 0.77 & $>100$ & Waldschmidt et al., 2016 \\
\hline $224406(12 n)$ & ND & ND & 0.13 & $>100$ & Waldschmidt et al., 2016 \\
\hline $215022(12 \mathrm{~h})$ & $0.21 \pm 0.05$ & $5 \pm 1$ & 0.15 & 0.38 & Waldschmidt et al., 2016 \\
\hline $257142(33)$ & $0.12 \pm 0.01$ & $6 \pm 1$ & 0.25 & 0.26 & Waldschmidt et al., 2018 \\
\hline Propanolol & $79 \pm 10$ & $31 \pm 2$ & NA & NA & \\
\hline Atenolol & $<0.4$ & $8 \pm 1$ & NA & NA & \\
\hline
\end{tabular}

NA, not applicable ND, not done; $P_{e}$, effective permeability; \%R, percent membrane retention.

by reducing phosphorylation of other residues on the C-terminal tail of MOR, such as Thr376 and Thr379.

\section{Discussion}

Replacement of the pyrazole of CCG258208 with an indazole to give CCG258747 resulted in a more potent GRK2 inhibitor $\left(\mathrm{IC}_{50}=18 \mathrm{nM}\right)$ with high selectivity over GRK1, GRK5, PKA, and ROCK1 (518-, 83-, >5500-, and $>550$-fold, respectively). The high selectivity of both inhibitors was further validated in a kinome selectivity scan wherein both CCG258208 and CCG258747 were able to inhibit GRK2 and GRK3 activity below $2.5 \%$ of control with very little off-target activity. Evaluation in a short pharmacokinetics study revealed that CCG258747, like CCG245208, was able to maintain plasma concentrations higher than its $\mathrm{IC}_{50}$ for over 7 hours, which was indicative of its potential as an in vivo therapeutic.

Crystallization of CCG258747 further shows that its indazole ring takes advantage of conformational flexibility in the hydrophobic subsite of GRK2, as evidenced by comparing the structure of GRK2-G $\beta \gamma$. CCG258747 to that of CCG258208. One might hypothesize that GRK2 has more latitude to accommodate bulky substituents within its hydrophobic subsite than the other GRK subfamilies or other kinases. However, this cannot explain the exceptional selectivity of CCG258747 for GRK2 subfamily members relative to the rest of the kinome because CCG258208, with the smaller pyrazole D-ring, is similarly selective. Instead, it selectively appears to be largely dictated by unique interactions of the benzodioxole ring with the GRK2 hinge, with the added van der Waals interactions with the indazole D-ring of CCG258747 contributing to enhanced potency. Indeed, the indazole substitution enhances potency against all GRKs tested relative to CCG258208 (Table 1).

A live-cell receptor internalization assay using MOR as a model system was used to test the ability of these inhibitors to function in cells, which we hypothesized would be a better read-out of their suitability for in vivo trials than $\mathrm{IC}_{50}$ values because it takes into account the ability of these compounds to cross the cell membrane in sufficient amounts to achieve levels at or above their GRK2 IC $_{50}$ in the cytosol. Overall, inhibitors with the piperidine B-ring of the paroxetine scaffold demonstrated much better efficacy than those based on the GSK180736A B-ring (Fig. 4), with CCG258747 demonstrating the highest efficacy of the inhibitors tested. Our results are consistent with other recent studies on the ability of paroxetine to inhibit phosphorylation of the $\beta_{2}$-AR and reduce internalization of the $\beta_{1}$ - and $\beta_{2}$-ARs in HEK293 and U2OS cells, respectively (Guo et al., 2017), thus demonstrating the utility of paroxetine analogs for inhibiting the proximal effects of GRKs in multiple cell types for multiple GPCRs. An assay for cell permeability similarly showed that paroxetine-based inhibitors in general also demonstrated

\begin{tabular}{|c|c|c|c|c|c|c|c|c|c|c|}
\hline \multirow[b]{2}{*}{ 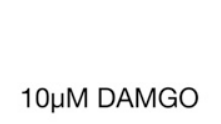 } & \multicolumn{4}{|c|}{ HEK293 } & \multirow[b]{2}{*}{+} & \multicolumn{4}{|c|}{ U2OS } & \\
\hline & - & + & + & + & & - & + & + & + & + \\
\hline $20 \mu \mathrm{M}$ Paroxetine & - & - & + & - & - & - & - & + & - & - \\
\hline $20 \mu \mathrm{M} 258208$ & - & - & - & + & - & - & - & - & + & - \\
\hline $20 \mu \mathrm{M} 258747$ & - & - & - & - & + & - & - & - & - & + \\
\hline
\end{tabular}

IB: $\mu$ OR pS375
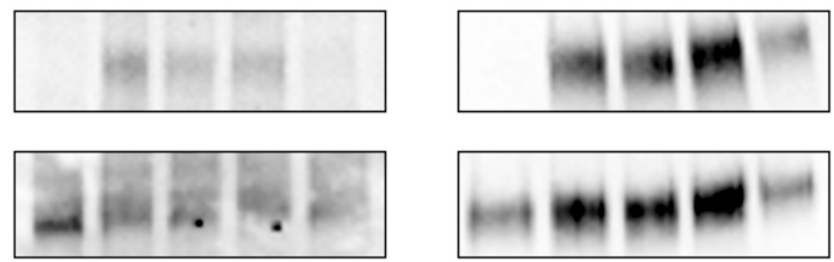

Fig. 5. Effect of GRK2 inhibitors on phosphorylation of MOR-Ser375. Cell lysates from MOR stable cell lines of either HEK293 (left) or U2OS (right) were blotted for phospho-Ser375 using an anti-pSer375-OPRM1 antibody (top blots) and blotted for total receptor (bottom blots) with an anti-OPRM1. For paroxetine, CCG258208, and CCG258747 treatments, the cells were pretreated with inhibitor for 20 minutes prior to the addition of DAMGO. IB, immunoblot. 
better cell permeability properties than the GSK180736A scaffold (Table 3). Thus, our assay can select for compounds that combine high GRK2 potency with favorable cell permeability.

Finally, we note that GRK inhibitors with potency against both GRK2 and GRK5 (marked with plus symbols in Fig. 4) in general were unable to inhibit MOR internalization better than those with high GRK2 selectivity. Cell permeability was far more predictive of efficacy. This result is consistent with our observation that phosphorylation of MOR at Ser375 is not significantly affected by GRK2 inhibition (Fig. 5; Supplemental Fig. 5), because this site is believed to be phosphorylated primarily by GRK5 (Doll et al., 2011; Just et al., 2013), whereas higher order phosphorylation at other sites is thought to be GRK2-mediated (Mann et al., 2015). A hierarchical model of MOR phosphorylation, in which Ser375 is phosphorylated with subsequent recruitment of GRK2 to phosphorylate other sites in the MOR C-terminal tail, has been previously proposed and recently demonstrated using in-cell assays to assess MOR recruitment of GRK2 (Just et al., 2013; Miess et al., 2018). Hierarchical phosphorylation is reportedly key for rapid receptor desensitization, high-affinity arrestin binding, and long-term receptor desensitization via receptor internalization (Miess et al., 2018; Sente et al., 2018). Thus, at least in these cell systems, our data suggest that phosphorylation of MOR by GRK2 subfamily members dominates arrestin recruitment and internalization. As data continue to gather implicating MOR phosphorylation as a primary mediator of drug-specific receptor tolerance in vivo (Arttamangkul et al., 2019; Kliewer et al., 2019), the chemical probes described in this study may prove to be important tools through their potential ability to selectively alter MOR phosphorylation in vivo.

\section{Acknowledgments}

The mouse liver microsome stability and short pharmacokinetic studies were executed by the University of Michigan Pharmacokinetics Core.

\section{Authorship Contributions}

Participated in research design: Bouley, Weinberg, Yen, Larsen, Puthenveedu, Tesmer.

Conducted experiments: Bouley, Weinberg, Waldschmidt, Yen.

Contributed new reagents or analytic tools: Waldschmidt.

Performed data analysis: Bouley, Weinberg, Waldschmidt.

Wrote or contributed to the writing of the manuscript: Bouley, Weinberg, Waldschmidt, Tesmer.

\section{References}

Afonine PV, Grosse-Kunstleve RW, Echols N, Headd JJ, Moriarty NW, Mustyakimov M, Terwilliger TC, Urzhumtsev A, Zwart PH, and Adams PD (2012) Towards automated crystallographic structure refinement with phenix.refine. Acta Crystallogr D Biol Crystallogr 68:352-367.

Arttamangkul S, Leff ER, Koita O, Birdsong WT, and Williams JT (2019) Separation of acute desensitization and long-term tolerance of $\mu$-opioid receptors is determined by the degree of C-terminal phosphorylation. Mol Pharmacol 96:505-514.

Avdeef A (2001) Physicochemical profiling (solubility, permeability and charge state). Curr Top Med Chem 1:277-351.

Bouley R, Waldschmidt HV, Cato MC, Cannavo A, Song J, Cheung JY, Yao X-Q, Koch WJ, Larsen SD, and Tesmer JJG (2017) Structural determinants influencing the potency and selectivity of indazole-paroxetine hybrid G protein-coupled receptor kinase 2 inhibitors. Mol Pharmacol 92:707-717.

Chen VB, Arendall WB III, Headd JJ, Keedy DA, Immormino RM, Kapral GJ, Murray LW, Richardson JS, and Richardson DC (2010) MolProbity: all-atom structure validation for macromolecular crystallography. Acta Crystallogr D Biol Crystallogr 66:12-21.

Davis MI, Hunt JP, Herrgard S, Ciceri P, Wodicka LM, Pallares G, Hocker M, Treiber DK, and Zarrinkar PP (2011) Comprehensive analysis of kinase inhibitor selectivity. Nat Biotechnol 29:1046-1051.

Doll C, Konietzko J, Pöll F, Koch T, Höllt V, and Schulz S (2011) Agonist-selective patterns of $\mu$-opioid receptor phosphorylation revealed by phosphosite-specific antibodies. Br J Pharmacol 164:298-307.
Dzimiri N, Muiya P, Andres E, and Al-Halees Z (2004) Differential functional expression of human myocardial $\mathrm{G}$ protein receptor kinases in left ventricular cardiac diseases. Eur J Pharmacol 489:167-177.

Emsley P and Cowtan K (2004) Coot: model-building tools for molecular graphics. Acta Crystallogr D Biol Crystallogr 60:2126-2132.

Fabian MA, Biggs WH III, Treiber DK, Atteridge CE, Azimioara MD, Benedetti MG, Carter TA, Ciceri P, Edeen PT, Floyd M, et al. (2005) A small molecule-kinase interaction map for clinical kinase inhibitors. Nat Biotechnol 23:329-336.

Fan X, Zhang J, Zhang X, Yue W, and Ma L (2002) Acute and chronic morphine treatments and morphine withdrawal differentially regulate GRK2 and GRK5 gene expression in rat brain. Neuropharmacology 43:809-816.

Ferguson SS, Downey WE III, Colapietro AM, Barak LS, Ménard L, and Caron MG (1996) Role of beta-arrestin in mediating agonist-promoted G protein-coupled receptor internalization. Science 271:363-366.

Gildea RJ, Waterman DG, Parkhurst JM, Axford D, Sutton G, Stuart DI, Sauter NK, Evans G, and Winter G (2014) New methods for indexing multi-lattice diffraction data. Acta Crystallogr D Biol Crystallogr 70:2652-2666.

Glück L, Loktev A, Moulédous L, Mollereau C, Law P-Y, and Schulz S (2014) Loss of morphine reward and dependence in mice lacking $\mathrm{G}$ protein-coupled receptor kinase 5. Biol Psychiatry 76:767-774.

Guo S, Carter RL, Grisanti LA, Koch WJ, and Tilley DG (2017) Impact of paroxetine on proximal $\beta$-adrenergic receptor signaling. Cell Signal 38:127-133.

Gurevich EV, Tesmer JJG, Mushegian A, and Gurevich VV (2012) G protein-coupled receptor kinases: more than just kinases and not only for GPCRs. Pharmacol Ther 133:40-69.

Gurevich VV and Gurevich EV (2019) GPCR signaling regulation: the role of GRKs and arrestins. Front Pharmacol 10:125.

Homan KT, Larimore KM, Elkins JM, Szklarz M, Knapp S, and Tesmer JJG (2015) Identification and structure-function analysis of subfamily selective G proteincoupled receptor kinase inhibitors. ACS Chem Biol 10:310-319.

Huang ZM, Gold JI, and Koch WJ (2011) G protein-coupled receptor kinases in normal and failing myocardium. Front Biosci 16:3047-3060.

Just S, Illing S, Trester-Zedlitz M, Lau EK, Kotowski SJ, Miess E, Mann A, Doll C, Trinidad JC, Burlingame AL, et al. (2013) Differentiation of opioid drug effects by hierarchical multi-site phosphorylation. Mol Pharmacol 83:633-639.

Kansy M, Senner F, and Gubernator K (1998) Physicochemical high throughput screening: parallel artificial membrane permeation assay in the description of passive absorption processes. J Med Chem 41:1007-1010.

Kliewer A, Schmiedel F, Sianati S, Bailey A, Bateman JT, Levitt ES, Williams JT, Christie MJ, and Schulz S (2019) Phosphorylation-deficient G-protein-biased $\mu$-opioid receptors improve analgesia and diminish tolerance but worsen opioid side effects. Nat Commun 10:367.

Kozasa T (2004) Purification of G protein subunits from Sf9 insect cells using hexahistidine-tagged alpha and beta gamma subunits. Methods Mol Biol 237: 21-38.

Mann A, Illing S, Miess E, and Schulz S (2015) Different mechanisms of homologous and heterologous $\mu$-opioid receptor phosphorylation. Br J Pharmacol 172:311-316.

McCoy AJ, Grosse-Kunstleve RW, Adams PD, Winn MD, Storoni LC, and Read RJ (2007) Phaser crystallographic software. J Appl Cryst 40:658-674.

Miess E, Gondin AB, Yousuf A, Steinborn R, Mösslein N, Yang Y, Göldner M, Ruland JG, Bünemann M, Krasel C, et al. (2018) Multisite phosphorylation is required for sustained interaction with GRKs and arrestins during rapid $\mu$-opioid receptor desensitization. Sci Signal 11:eaas9609.

Quillinan N, Lau EK, Virk M, von Zastrow M, and Williams JT (2011) Recovery from mu-opioid receptor desensitization after chronic treatment with morphine and methadone. J Neurosci 31:4434-4443.

Rajagopal S and Shenoy SK (2018) GPCR desensitization: acute and prolonged phases. Cell Signal 41:9-16.

Rockman HA, Choi DJ, Akhter SA, Jaber M, Giros B, Lefkowitz RJ, Caron MG, and Koch WJ (1998) Control of myocardial contractile function by the level of beta-adrenergic receptor kinase 1 in gene-targeted mice. J Biol Chem 273 : $18180-18184$

Salazar NC, Chen J, and Rockman HA (2007) Cardiac GPCRs: GPCR signaling in healthy and failing hearts. Biochim Biophys Acta 1768:1006-1018.

Sankaranarayanan S, De Angelis D, Rothman JE, and Ryan TA (2000) The Use of pHluorins for Optical Measurements of Presynaptic Activity. Biophysical Journal 79:2199-2208, doi: 10.1016/S0006-3495(00)76468-X 11023924.

Schindelin J, Arganda-Carreras I, Frise E, Kaynig V, Longair M, Pietzsch T, Preibisch S, Rueden C, Saalfeld S, Schmid B, et al. (2012) Fiji: an open-source platform for biological-image analysis. Nat Methods 9:676-682.

Sente A, Peer R, Srivastava A, Baidya M, Lesk AM, Balaji S, Shukla AK, Babu MM, and Flock T (2018) Molecular mechanism of modulating arrestin conformation by GPCR phosphorylation. Nat Struct Mol Biol 25:538-545.

Singh P, Wang B, Maeda T, Palczewski K, and Tesmer JJG (2008) Structures of rhodopsin kinase in different ligand states reveal key elements involved in $\mathrm{G}$ protein-coupled receptor kinase activation. J Biol Chem 283:14053-14062.

Soohoo AL and Puthenveedu MA (2013) Divergent modes for cargo-mediated control of clathrin-coated pit dynamics. Mol Biol Cell 24:1725-1734, doi: 10.1091/mbc.E1207-0550 23536704

Thal DM, Homan KT, Chen J, Wu EK, Hinkle PM, Huang ZM, Chuprun JK, Song J, Gao E, Cheung JY, et al. (2012) Paroxetine is a direct inhibitor of g protein-coupled receptor kinase 2 and increases myocardial contractility. ACS Chem Biol 7: 1830-1839.

Thal DM, Yeow RY, Schoenau C, Huber J, and Tesmer JJG (2011) Molecular mechanism of selectivity among $\mathrm{G}$ protein-coupled receptor kinase 2 inhibitors. Mol Pharmacol 80:294-303.

Violin JD, Ren X-R, and Lefkowitz RJ (2006) G-protein-coupled receptor kinase specificity for beta-arrestin recruitment to the beta2-adrenergic receptor 
revealed by fluorescence resonance energy transfer. $J$ Biol Chem 281: 20577-20588.

Vistein R and Puthenveedu MA (2013) Reprogramming of G protein-coupled receptor recycling and signaling by a kinase switch. Proc Natl Acad Sci USA 110:15289-15294. Waldschmidt HV, Bouley R, Kirchhoff PD, Lee P, Tesmer JJG, and Larsen SD (2018) Utilizing a structure-based docking approach to develop potent $\mathrm{G}$ protein-coupled receptor kinase (GRK) 2 and 5 inhibitors. Bioorg Med Chem Lett 28:1507-1515.

Waldschmidt HV, Homan KT, Cato MC, Cruz-Rodríguez O, Cannavo A, Wilson MW, Song J, Cheung JY, Koch WJ, Tesmer JJ, et al. (2017) Structure-based design of highly selective and potent $\mathrm{G}$ protein-coupled receptor kinase 2 inhibitors based on paroxetine. J Med Chem 60:3052-3069.

Waldschmidt HV, Homan KT, Cruz-Rodríguez O, Cato MC, Waninger-Saroni J, Larimore KM, Cannavo A, Song J, Cheung JY, Kirchhoff PD, et al. (2016) Structure-based design, synthesis, and biological evaluation of highly selective and potent G protein-coupled receptor kinase 2 inhibitors. J Med Chem 59:3793-3807.

Weinberg Z (2019) Ensemble-recycling, Zenodo, doi: 10.5281/zenodo.2645754.
Woodall MC, Ciccarelli M, Woodall BP, and Koch WJ (2014) G protein-coupled receptor kinase 2: a link between myocardial contractile function and cardiac metabolism. Circ Res 114:1661-1670.

Woodall MC, Woodall BP, Gao E, Yuan A, and Koch WJ (2016) Cardiac fibroblast GRK2 deletion enhances contractility and remodeling following ischemia/reperfusion injury. Circ Res 119:1116-1127.

Yang X, Huang Y, Crowson M, Li J, Maitland ML, and Lussier YA (2010) Kinase inhibition-related adverse events predicted from in vitro kinome and clinical trial data. J Biomed Inform 43:376-384.

Address correspondence to: John J.G. Tesmer, Departments of Biological Sciences and of Medicinal Chemistry and Molecular Pharmacology, Purdue University, 915 W. State St., HOCK 329, West Lafayette, IN 47907. E-mail: jtesmer@purdue.edu 